Research Article

\title{
Evaluation of Genetic Diversity in Barley Landraces through Agro- Morphological and Biochemical Characterization
}

\author{
Arshad Khan ${ }^{1}$, Mohammad Ihsan ${ }^{1}$, Mohammad Nisar ${ }^{1}$, Ali Hazrat ${ }^{1 *}$, Murad Ali ${ }^{3}$, Rashid U1-Haq ${ }^{3}$, Khalid \\ Khan $^{2}$, Karishma Gul ${ }^{1}$ and Shah Faisal ${ }^{1}$
}

${ }^{1}$ Department of Botany, University of Malakand, Chakdara, Dir Lower, Khyber Pakbtunkhwa, Pakistan; ${ }^{2}$ Islamia College, University of Peshawar, Khyber Pakhtunkhwa, Pakistan; ${ }^{3}$ Department of Botany, Hazara University Mansehera, Khyber Pakbtunkhwa, Pakistan.

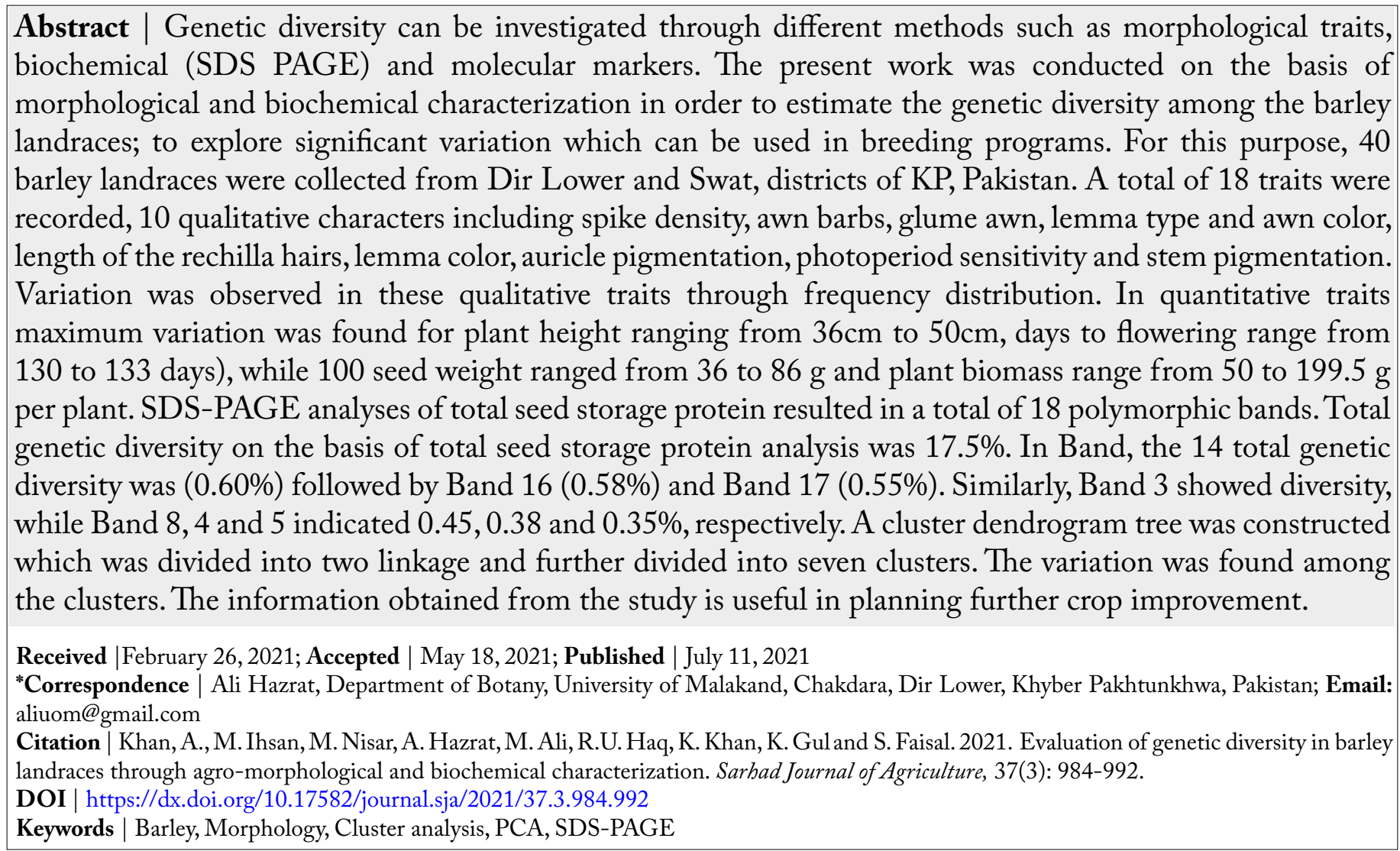

\section{Intorduction}

$\mathrm{B}$ arely is an important cereal crop and ranks around fourth in the world cereal production statistics following wheat, maize and rice (USDA-2008). It is estimated that annually over 133.85 million tones barley is produced worldwide. Barley is used as feed, food and for the brewing and distilling industries
(Morris and Bryce, 2000). Barley is containing 80\% carbohydrates which is an important source of energy. In the roman times, barley was the most popular food of providing a high energy, before going to the circus. The gladiators were fed on barley diet, so they were called "hordeari" from hordeium. Researchers also found that the amount of cholesterol in humans is decreased in blood serum due to the consistency of 
non-starch polysaccharides in barley, also known as glucans (Zeeshan et al., 2012).

As well as being more important to humans, barley is a major nutritional part of the human diet, contributing to a significant portion of the global human diet. Barley is also used as beer and fodder form of animal feed (Finnie and Svensson, 2009). Due to barley tolerant, various environmental factor it adopt itself. Barley is distributed all over the globe in different areas such as the sub-Arctic, cooler tropical highlands and subtropics, temperate climates, high altitudes and saline soils of the maritime zone. Indeed, one of the few areas where barley is not found on Earth is the tropical lowlands because it is more hot and humid regions on earth (Ali et al., 2020). As early as 13,000 years ago in Eurasia (Ukraine) the first cultivated plant was barley. In various cultures barley used in soups and stews and barley bread. Barley grains are commonly made into malt in a traditional and ancient method of preparation (Zohary and Hopf, 2020).

In order to effectively conserve, evaluate, and use germplasm, researchers must look into the estimate of genetic variation available. Genetic diversity is an integral aspect of any agricultural production system, in breeding, modification in germplasm effectively, the investigation of genetic diversity important, in the first part of the last century, recognized the importance of genetic variation in the germplasm of crop organisms (Smykal et al., 2018). Morphological characterization is considered an important step in description and classification of crop germplasm because a breeding program depends on the magnitude of genetic variability, among biochemical techniques, Sodium Dodecyl Sulphate Poly acryl amide Gel Electrophoresis (SDS-PAGE) is most widely used due to its validity and simplicity for describing genetic structure of crop germplasm (Raza et al., 2020). The development of cultivars with enhanced agronomic characteristics is most easily accomplished in genetically diverse plants. Consequently, the presence and estimation of genetic variability within such organisms is important for plant breeding programs (Ghafoor et al., 2005). Genetic variation within and between crop populations is determined by techniques such as morphological characterization, Protein profiling and DNA (or molecular) marker analysis (Nisar et al., 2008; Ghafoor and Arshad, 2008).

One important step forward is the assessment of diversity among varieties and section of best variety. To analyze diversity, molecular techniques such as protein electrophoresis due to high polymorphism and morphological characterization are acceptable methods. Via morphological characterization, total seed storage proteins and selection of elite (high yielding) genotypes, the purpose of this study is to estimate genetic diversity among 40 barley landraces.

\section{Materials and Methods}

The present work was carried out under field condition in the Department of Botany, Botanical Garden University of Malakand, KP, Pakistan. Total of 40 landraces were evaluated for both morphological and biochemical characterizations. The seeds were collected from various locations of District Dir and Swat that represent a wide range of ecological zones from dry mountains to irrigated plains. The Landraces were planted on October 28, 2019. Block field design was used for the experiment (following Randomized Completer Blocked Design with three replicates), the row length was $2 \mathrm{~m}$ with $20 \mathrm{~cm}$ space between rows. Each genotype was planted in adjacent rows, where intra variety distance (between the seed) was $12 \mathrm{~cm}$.

\section{Morphological/ agronomic characterization}

Both quantitative and qualitative traits were measured. 10 were qualitative which are Aluerone color, Lemma color, Grain color, Awn color, Awn barbs, Kernel covering, Seed color (SC), Glumes color, Stem pigmentation, Auricle pigmentation, Length of rechilla hairs, Lemma type, Lemma with awn, Glume and Glume Awns, and 8 quantitative traits which are Days to germination (DG), Days to Flowering (DF), Days to Maturity (DM), Plant height, Spike length, Seed per spike, 100 Seed Weight, biomass/plant.

\section{Biochemical characterization}

All the collected genotypes used in agro morphological characterizations, subject to the total seed storage proteins based on SDS-PAGE analyses. Five healthy and mature seeds with mortar and pestle were ground manually. A sample of $0.02 \mathrm{~g}$ grinded was weighed and transferred to $1.5 \mathrm{ml}$ centrifuge tubes, where the tube was added with a $400 \mu$ protein extraction buffer. The powder was homogenized at room temperature for 1 minute before centrifugation at $12,000 \mathrm{rpm}$ for 10 minutes (RT). The $12.25 \%$ polyacrylamide gels were used for total seed protein, following Laemmli's 1970 protocol (He, 2011). 
Table 1: Descriptive statistics for eight quantitative character of 40 barley genotype.

$\begin{array}{llllllll}\text { Parameters } & \text { Mean } & \begin{array}{l}\text { Standard } \\ \text { error }\end{array} & \begin{array}{l}\text { Standard } \\ \text { deviation }\end{array} & \text { Sample variance } & \text { Minimum } & \text { Maximum } & \text { CV\% } \\ \text { Days to maturity } & 178.4 & 1.05 & 6.65 & 44.25 & 167 & 185 & 3.73 \\ \text { Days to flowering } & 140.6 & 0.74 & 4.7 & 22.09 & 133 & 146 & 3.34 \\ \text { Plant height } & 43.78 & 0.6 & 3.77 & 14.23 & 36 & 50 & 8.62 \\ \text { Spike length } & 10.4 & 0.22 & 1.41 & 1.99 & 7 & 13 & 13.56 \\ \text { Seed per spike } & 72.25 & 2.38 & 15.07 & 227.12 & 36 & 108 & 20.86 \\ \text { 100seed weight } & 56.59 & 2.09 & 13.21 & 174.45 & 37.9 & 86.5 & 23.34 \\ \text { Biomass/plant } & 119.3 & 7.95 & 50.27 & 2526.77 & 50 & 199.6 & 42.13\end{array}$

Table 2: Correlation among the eight quantitative traits of 40 germplasm.

$\begin{array}{lllllllll}\text { Parameters } & \text { DM } & \text { DF } & \text { PH } & \text { SPKL } & \text { S/SPK } & \text { 100 SWT } & \text { BM } & \text { HI } \\ \text { DM } & 1 & & & & & & & \\ \text { DF } & .387^{*} & 1 & & & & & & \\ \text { PH } & 0.125 & .689^{* *} & 1 & & & & & \\ \text { SPKL } & -0.05 & -0.169 & -0.118 & 1 & & & \\ \text { S/SPK } & 0.007 & -0.017 & 0.027 & -0.051 & 1 & & \\ \text { 100SWT } & -0.208 & -.557^{* *} & -.524^{* *} & 0.083 & -0.11 & 1 & \\ \text { BM } & 0.198 & 0.239 & .340^{*} & 0.022 & -0.142 & -0.139 & 1 & \\ \text { HI } & 0.193 & 0.208 & 0.02 & 0.04 & 0.001 & -0.204 & .553^{* *} & 1\end{array}$

Five plants were randomly selected to measure genetic diversity, and then the mean value of each genotype was used for data analysis. Using Microsoft Excel, Basic statistics were computed (mean, maximum, minimum, and coefficient of variance). Using cluster and main component analysis, a total of 14 morphological characteristics were identified and analyzed. Correlation analysis was estimated using Statistica 7 and version 2.1 of NTSys PC (Applied Biostatistics Inc, USA). Binary matrix data for total seeds storage proteins were measured as band presence and absence. Dendogram was computed using the unweighted pair group approach with the arithmetic average (UPGMA) algorithm for cluster analysis. For possible pairs of electrophograms, the electrophoresis band spectra and similarity index were computed.

\section{Results and Discussion}

Genetic diversity based on agro morphological characterization. During the present study both quantitative (8) and qualitative (10) traits were studied in the collected genotypes of Barley from Dir Lower and Swat districts. The purpose of the study to identify with the aid of morphological character the genetic diversity among the barley genotypes and to find out high yielding genotype using protein profiling. During the present analysis (correlation analysis Principal Component Analysis and Cluster analysis) of both qualitative and quantitative traits of 40 barley genotypes were examined. Morphological and agronomic characteristics of the germplasm collected promote the identification and selection of suitable characteristics (Ghafoor et al., 2002; Khan et al., 2019).

\section{Quantitative parameters}

During the present study eight quantitative characters were studied as presented in Table 3, such as, days to maturity, days to flowering, plant height, spike length, seed per spike, 100 seed weight, biomass per plant, harvest index. Mean value, standard error, standard deviation, sample variance, minimum, maximum and $\mathrm{CV} \%$ as presented in Table 3. During the present study a significant diversity was found in days to flowering, early (130 to 133 days), moderate (137 to 138 days) and high (144 to 146 ). With the mean value of 140.60 and sample variance 22.09. A wide range of variation were noted for days to maturity with the range of 167 to 185 days, with the mean value of 178.40 and sample variance 44.25 . During the present a number of variation was found for spike length, low (range from 7-9 cm), medium (range 10$11 \mathrm{~cm}$ ) and high (range from 12-13 cm) with mean 
value of 10.40 and sample variance 1.99. Maximum no. of landraces had medium spike length (55\%) followed by low spike length (25\%) and high spike length (20\%). In case of plant height, there was a wide range of variability found among the landraces. The range of plant height between $36 \mathrm{~cm}$ to $50 \mathrm{~cm}$, with mean value of 43.78 , and sample variance of 14.23 . Low (36 to $40 \mathrm{~cm}$ ), medium (41 to $44 \mathrm{~cm}$ ) and high (45 to $50 \mathrm{~cm}$ ). The number of seed per spike in 40 landraces are divided into three categories, low (36 to 72 ) medium (72 to 80 ) and high (82 to 108), with the mean value of 72.25 and sample variance 227.12. A wide range of variation was found among the landraces on the base of 100 seed weight. Range from $37 \mathrm{~g}$ to $86.5 \mathrm{~g}$ with mean value of 56.59 and sample variance 174.45.Significant variation was observed during the study on the base of biomass per plant range from (50 to 199.5). In present study, high variation was found in spike length (from 7 to $11 \mathrm{~cm}$ show $80 \%$ ) in barley germplasm. Lasa et al. (2001) investigated the morphological characterization, both qualitative and quantitative traits, which shown similarities and variation like present study, especially in kernel covering. Shegaw et al. (2013) also reported a wide range of variation in plant height, days to maturity and grain yield. Similarly, (Alemayehu and Parlevliet, 1997), reported days to maturity, plant height, during this present study the germplasm had broad range of days to maturity (167 to 185 days) and plant height $(36 \mathrm{~cm}$ to $50 \mathrm{~cm}$ ). The results of this study are very much in accordance with those of Gerano et al. (2014) assessed 22 morphological variability accessions for sorghum. Nine qualitative and 20 quantitative parameters were studied and found to be highly diversed in agro-morphological characters, including panicle compactness and shape, glume color, flowering days to $50 \%$, plant height, panicle width, grain yield, seed color and leaf midrib color.

\section{Qualitative traits}

During the present study, a total of 10 qualitative traits were studied. On the base of spike density, there are two types of spike density (lax and dense) were observed. In 40 landraces of barley, the frequency of lax $(15 \%) 6$, while frequency of intermediate was (85\%) 34, which show divergence among the landraces. Among the 40 landraces the awn barbs found are smooth which have (87.5\%) frequency 35 , intermediate (12.5\%) frequency 5 . The glume with awn length compare kernel length glumes and awn shorter then kernel, which present in (40\%). In 16 landraces (out of 40), length of the glumes and awn longer then kernel with frequency (27.5\%). In 11 and glume plus awn longer then kernel with a frequency (12.5\%), and in 5 showed variation among these landraces. A wide range of variability found in lemma type, on lemma have no teeth was found with frequency (22.5\%) 9 and lemma with teeth with frequency $(77.5 \%)$. The lemma color, normal (green color) with frequency (95\%) 38, red color frequency had (2.5\%) and purple color with frequency (2.5\%) (Table 1). In case of awn color, the white color was found with frequency of (17.5\%) 7 , the yellow color with frequency of $(77.5 \%)$ 31 , reddish color had (5\%) 2 . The length of rechilla hairs was recorded which are of two types, long hair with frequency (52.5\%) 21 and short with frequency (47.5\%) 19.There were three type color on the base of auricle pigmentation, which were observed in these landraces, the dark purple color were not found, the green color was found with frequency (90\%) 36, pale purple with frequency (7.5\%) 3 and the purple color had 1 with $2.5 \%$. There were three type of stem pigmentation was found, 5 with green color (12.5\%), 32 with purple color (80\%) and 3 of them was with purple color (half or more) $7.5 \%$ (Table 1). Zeeshan et al. (2012) studied 151 accessions of barely for agro morphological variation. A total of 4 traits were quantitative and 10 were qualitative with a significant variation. It includes spike density, glume color, awn roughness, awn color, number of spikelet per spike, rows of per spike, glume and glume awns, kernel covering, lemma color, rechilla hairs, grain color, awn length, 100 seed weight, spike length.

\section{Correlation analysis}

Correlation analysis of 40 landraces was conducted for eight agro-morphological characters by SPSS 16.1. During the present study days to flowering was found significantly correlated with days to maturity with the value of $.387^{*}$, followed by plant height found strongly significant with days to flowering. 100 seed weight 0 was found negatively correlated with days to flowering $-.557^{* *}$ and plant height with the value of $-.524^{* *}$. Similarly, plant biomass was found significantly correlated with plant height with the value of $.340^{*}$ and harvest index was found strongly negatively with plant biomass with the value of $-.553^{* *}$ respectively (Table 2 ). The same result was obtained by Eshaghi (2009) also reported the same result for the positive and negative correlation of the barley germplasm for this study he used 63 genotype for agro morphological and biochemical variation 
among barley germplasm. Ebrahim et al. (2015) also investigate the same result of correlation for quantitative traits of 20 genotype of barley germplasm. Similar results for grain yield and plant height in barley were reported by other studies (Kisana et al., 1999; Wisal et al., 2109; Arshad et al., 2019).

Table 3: Principal component analysis of 9 quantitative traits of 40 Barely landraces.

$\begin{array}{lllll}\text { AXIS } & \text { PC1 } & \text { PC2 } & \text { PC3 } & \text { PC4 } \\ \text { \% of Variance } & 38.25 & 18.12 & 14.18 & 10.69 \\ \text { Cum. \% of Var. } & 38.25 & 56.37 & 70.55 & 81.24 \\ \text { Eigenvalue } & 2.829 & 1.829 & 1.329 & 0.996 \\ \text { DM } & -0.34 & 0.608 & 0.009 & 0.015 \\ \text { DG } & -0.34 & 0.608 & 0.009 & 0.015 \\ \text { DF } & -0.43 & -0.08 & -0.25 & -0.13 \\ \text { PH } & -0.38 & -0.33 & -0.2 & -0.04 \\ \text { SL } & 0.077 & 0.025 & 0.428 & 0.695 \\ \text { Sp/s } & 0.006 & 0.013 & -0.51 & 0.679 \\ 100 \mathrm{~W} & 0.352 & 0.206 & 0.313 & -0.15 \\ \mathrm{Bm} / \mathrm{p} & -0.37 & -0.17 & 0.511 & 0.043 \\ \mathrm{Hi} & 0.424 & 0.265 & -0.3 & -0.11\end{array}$

\section{Principal component analysis}

Principle component analysis was conducted based on morphological traits of different Barely genotypes. It was observed that the total variation was $81.24 \%$ with the Eigen value of $0.99 \%$ (Table 3; Figure 1). In PC1 the total variation was $38.25 \%$ and it was found that days to maturity- 0.34 , days to germination- 0.34 , days to flowering-0.43, plant height -0.38 and biomass -0.37 were found negative weight while seed length -0.07 , seed per spike 0.006 were found positive weight. In PC2 the total variation was $56.37 \%$ and it was observed that days to maturity 0.60 , days to germination 0.60 , seed length $0.02,100$ seed weight 0.20 and harvest index 0.26 were found positive while days to flowering -0.08 , plant height -0.33 and plant biomass -0.17 were found negative weight. In addition, the total variation in PC3 was $70.55 \%$ and it was found that days to maturity 0.09 , days to germination 0.08 , seed length $0.42,100$ seed weight 0.31 and biomass 0.51 were found positive while the remaining traits days to flowering -0.25 , plant height -0.20 , and seed per spike -0.51 were contributed negative weight. Similarly, in PC4 the total variation was $681.24 \%$ and the contribution of days to maturity 0.01 , days to germination 0.01 , seed length 0.69 , seed per spike 0.67 and biomass 0.04 were found positive while days to flowering -0.13 , plant height -0.04 and harvest index -0.11 were found negative weight in PC4. (Table 3). Similarly, the scattering plot is also closely related for morphological analyzes which show genetic heterogeneity in the 40 genotypes in quantitative traits and similarities between closely associated genotype, which demonstrates similarity. The scatter plot was divided into two groups in term of direction. Mzid et al. (2016) who reported different quantitative traits in his study.

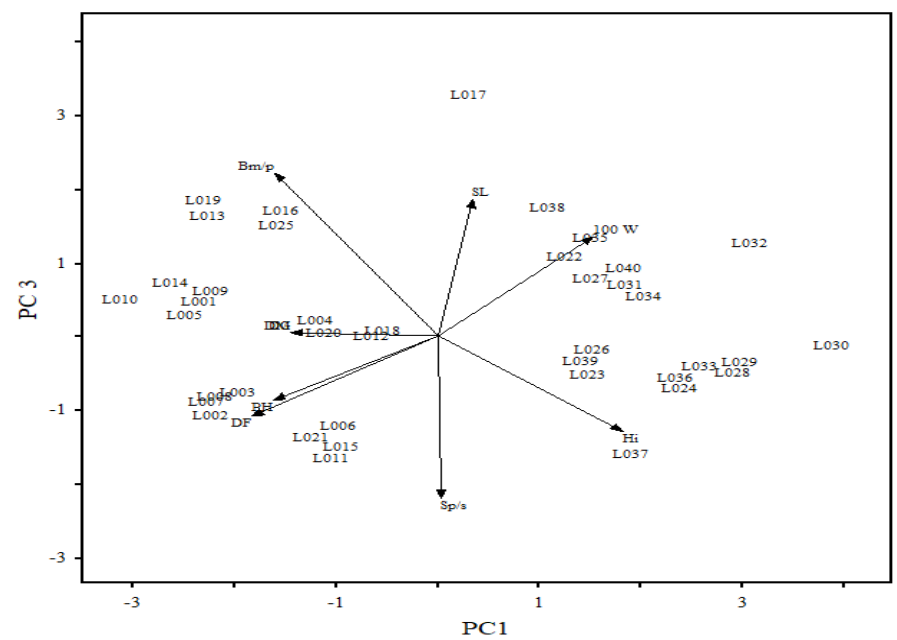

Figure 1: Scatter diagram of PC1 and PC3 of agro morphological traits of Barely genotypes.

\section{Total seed storage proteins}

To find out the genetic divergence in the landraces, SDS PAGE was used. It was found that genotypes showed substantial levels of genetic divergence on the basis of protein studies. Fifteen percent polyacrylamide gel was used during the current work. A total of 18 polymorphic subunit were observed. The total genetic diversity found in Barley was $\mathrm{f}$ 17.5 percent. In Band 14 the genetic variation was (0.60\%), followed by Band 16 (0.58\%), Band 17and Band10 was (0.55\%) and Band 2, Band 11, Band 12, Band 15 (0.53\%) polymorphism respectively. Band 1, Band 6, Band 18 (0.50\%), Band 7 and Band 13 (0.48\%), Band $8(0.45)$, Band 4, Band $9(0.38 \%)$ and Band 5 (0.35\%). Similarly, Band 3 revealed low level of genetic variation (0.33\%). Here the binary data matrix of total seed storage protein a cluster dendrogram was constructed and all the 40 genotypes were divided into 2 main lineages at a distance of $12.5 \%$ and further divided into 7 sub cluster. Lineage 1 divided into 5 sub cluster while lineage 2 divided into 2 sub cluster. Each cluster members shows less variation to one another but shows high number of genetic variation to the members of the other groups. 
Figure 2 cluster 1 of lineage 1 consists of 8 landraces, such as (L001, L008, L011, L002, L005, L007, L010, L040), cluster 2 contain 3 landraces (L003, L022, L033), cluster 3 contain 4 landraces (L012, L016, L014, L017) cluster 4 also contain7 landraces (L013, L015, L026, L021, L024, L035, L027), cluster 5 contain 7 landraces (L018, L029, L032, L020, L038, L028, L031), cluster6 contain 4 landraces (L004, L006, L009, L039) and cluster 7 had contain consist of 7 landraces (L016, L025, L030, L037, L023, L034, L036). Total seed protein analysis based on SDSPAGE play an important role in estimation of genetic diversity (Zahoor et al., 2015). It was estimated since several years that the morphological character of the different crop species (Nisar et al., 2016), but the biochemical methods of genetic diversity are now more beneficial than classical morphology (Akdeniz et al., 2004). PAGE for SDS Different plant grains have already been produced by electrophoresis of seed protein (Ghafoor et al., 2002; Nisar et al., 2008, 2009; Hameed et al., 2009). SDS-PAGE is a biochemical technology used to identify the genetic structure of different plants because it is simple, reliable and free of fluctuations. Protein profiling (Ghafoor et al., 2005). Researchers approved the valid evidence for detection of intra-specific variation and evaluation of inter-specific relationships in the SDS PAGE biochemical protein analysis (Hameed et al., 2009; Irfan et al., 2010). SDS PAGE data was not suited for analysis, according to (Zeeshan et al., 2012) says that it worked on the 200 barley accession, but bands were not clear.

Similarly, in other crops (Abdul and Tahir, 2014) who study 23 genotype pea total 21 bands was found which show variation. In present study of Barely a significant variation was observe in bands 14 (60\%) and Band 16 (58\%). The variation in protein bands express the genetic diversity present in the seed storage protein, the selection of elite variety or improvement in crops are depend on genetic variation (Figure 1). Daniele et al. (2015), according to this when the genetic diversity high in a species then higher the chance of improvement in that species. Dendogram of the population, Different landraces that are genetically different from each other are discriminated against by a separate cluster in a tree in different classes or genetically identical genotypes (Govindaraj et al., 2015).PCA is a multivariate method that is employed to complement the cluster analysis information and produce a dimensional germplasm scatter plot more descriptive of genotype distance (Hassan et al., 2016). For the current analysis, PCA (scatter plot) also showed variations between lands that were divided into different classes based on their similarities and differences (Figure 2).

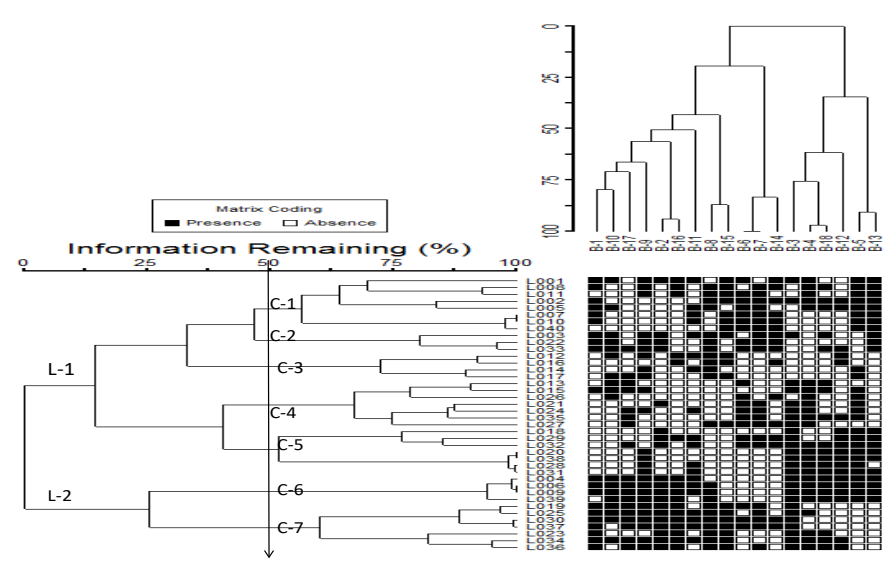

Figure 2: Dendogram tree for the protein data profiling of 40 landraces of barley.

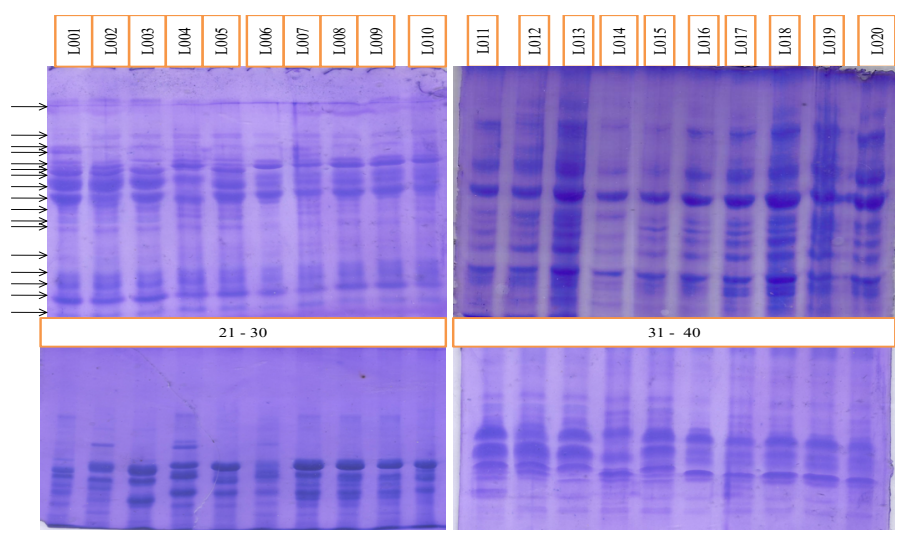

Figure 3: The gel show the protein bands pattern and their existing, of 10 landraces out of 40 germplasm of barley.

The landraces were collected from the districts of Dir Lower and Swat, KP- Pakistan. Passport information of the collected genotypes was presented in Table 4.

\section{Conclusions and Recommendations}

It was concluded for investigation of genetic divergence, ten qualitative traits utmost level of variation was found. In case of quantitative characters, maximum variation was found for plant height and days to flowering, while minimum variation was observed for 100 seed weight. A considerable variation was observed in SDS-PAGE analyses of seed storage protein given significant result. In 18 Bands, variation was observed among the clusters. It was suggested that representative landraces from different clusters could be chosen for the future breeding program. 
Table 4: Passport information of the present genotypes.

\begin{tabular}{|c|c|c|}
\hline Genotype no. & Location name & District \\
\hline L001 & Serai & Dir lower \\
\hline L002 & Tarnao & Dir lower \\
\hline L003 & Kityari & Dir lower \\
\hline L004 & Birand & Dir lower \\
\hline L005 & Bagh derai & Dir lower \\
\hline L006 & Danda & Dir lower \\
\hline L007 & Asbanr & Dir lower \\
\hline L008 & Khawas & Dir lower \\
\hline L009 & Khadagzai & Dir lower \\
\hline L010 & Khadang talash & Dir lower \\
\hline L011 & Osakai & Dir lower \\
\hline L012 & Taknai & Dir lower \\
\hline L013 & Kabaloo & Dir lower \\
\hline L014 & Bnada talash & Dir lower \\
\hline L015 & Dando shah & Dir lower \\
\hline L016 & Fazal mamond & Dir lower \\
\hline L017 & Hashm monda & Dir lower \\
\hline L018 & Ughaz & Dir lower \\
\hline L019 & Nawagi & Dir lower \\
\hline L020 & Seyyah & Dir lower \\
\hline L021 & Batkhela & Malakand \\
\hline L022 & Kamala & Malakand \\
\hline L023 & Sogyar & Malakand \\
\hline L024 & Pirana & Malakand \\
\hline L025 & Aladand & Malakand \\
\hline L026 & Nagram & Dir upper \\
\hline L027 & U-1 & Dir upper \\
\hline L028 & $\mathrm{U}-2$ & Dir upper \\
\hline L029 & Bahrain & Swat \\
\hline L030 & Madayn & Swat \\
\hline L031 & Kalkot & Swat \\
\hline L032 & Beshagram & Swat \\
\hline L033 & Shegal & Swat \\
\hline L034 & Durshkhela & Swat \\
\hline L035 & Matta & Swat \\
\hline L036 & Sakhra & Swat \\
\hline L037 & Bartana & Swat \\
\hline L038 & Sinpora & Swat \\
\hline L039 & Nalkot & Swat \\
\hline L040 & Chupral & Swat \\
\hline
\end{tabular}

\section{Novelty Statement}

This study aimed to identify diversity in barley landraces in the hilly areas. This activity was novel and was not carried out in this area.

\section{Author's Contribution}

Arshad Khan: Result collection and field work, objective and title configuration.

Mohammad Ihsan and Mohammad Nisar: Result calibration with softwares.

Ali Hazrat and Murad Ali: Discussion calibration with result.

Rashid U1-Haq: Helped in collection of data from the field.

Khalid Khan: References designing according to the journal standard.

Karishma Gul: Review of literature.

Shah Faisal: Overall compilation of the paper

\section{Conflict of interest}

The authors have declared no conflict of interest.

\section{Refrence}

Abdul, R. and N. Tahir. 2014. Comparison of Rapd-PCR and SDS-Page techniques to evaluate genetic variation among nine barley varieties (Hordeum spp.). Malays Appl. Biol., 43(1): 107-117.

Akdeniz, H., B. Keskin, I. Y1lmaz and E. Oral. 2004. A research on yield and yield components of some barley cultivars. J. Agric. Sci., 14: 119125.

Alemayehu, F. and J.E. Parlevliet. 1997. Variation between and within Ethiopian barley landraces. Euphytica, 94: 183-189. https://doi. org/10.1023/A:1002946004268

Ali, M., H. Manzoor, A. Saeed, K. Waqar and M. Nisar. 2020. Integrated scoring of salinity stress on agro-morphometric and seed storage proteins in barley landraces. Pure Appl. Biol., 9(1): 964-978. https://doi.org/10.19045/ bspab.2020.90011

Arshad, K., M.A., Ul-Haq, R., Khan, K., Gul, K., Khan, A., Khan, I. and Iqbal, M. 2019. Evaluation of wild Rhynchosia minima (L.) DC. through morphometric and biochemicalmarkers. Int. J. Biosci.14: 7-15. http://dx.doi.org/10.12692/ijb/14.3.7-15

Daniele, O.B., F.U. Sousa, J.T.A. Carvalho, D.F. Oliveira, I.C. Farias, H.P. Oliveira and M.V. Ilka. 2015. Increased levels of anti-nutritional and/or defense proteins reduced the protein quality of a disease-resistant soybean cultivar. Nutrients, 7(7): 6038-6054. https://doi. 
org/10.3390/nu7075269

Ebrahim, S., E. Shiferaw and F. Hailu. 2015. Evaluation of genetic diversity in barley (Hordeum vulgare L.) from Wollo high land areas using agro-morphological traits and hordein. Afr. J. Biotechnol., 14(22): 217-225.

EshghiR.andE.Akhundova.2009.Genetic diversity in hulless barley based on agromorphological traits and RAPD markers and comparison with storage protein analysis. Afr. J. Agric. Res., 5(1): 097-107.

Finnie, C. and B. Svensson. 2009. Barley seed proteomics from spots to structures. J. Proteom., 72: 315-324. https://doi.org/10.1016/j. jprot.2008.12.001

Gerano A.S., M.T. Labuschagne, A.V. Biljon and N.G. Shargie. 2014. Genetic variability among sorghum accessions for seed starch and stalk total sugar content. Sci. Agric., 71: 472-479. https://doi.org/10.1590/0103-9016-20130322

Ghafoor, A., and M. Arshad. 2008. Seed protein profiling of Pisumsativum (L) germplasm using Sodium dodecyl sulphate polyacrylamide gel electrophoresis (SDS-PAGE) for investigation of biodiversity. Pak. J. Bot., 40(6): 2315-2321.

Ghafoor, A., Z. Ahmad and M. Afzal. 2005. Use of SDS-PAGE markers for determining quantitative traits loci in blackgram [Vigna mungo (L.) Hepper] germplasm. Pak. J. Bot., 37(2): 263-269.

Ghafoor, A., Z. Ahmad, A.S. Qureshi and M. Bashir. 2002. Genetic relationship in Vigna mungo (L.) Hepper and $V$. Radiate (L.) R. Wileczek Based on Morphological Traits and SDS-PAGE. Euphytica, 23: 378.

Govindaraj, M., M. Vetriventhan and M. Srinivasan. 2015. Importance of genetic diversity assessment in crop plants and its recent advances: An overview of its analytical perspectives, Genet. Res. Int., 20: 14. https:// doi.org/10.1155/2015/431487

Hameed, A., T.M. Shah, B.M. Atta, N. Iqbal, M.A. Haq and H. Ali. 2009. Comparative seed storage protein profiling of Kabuli chickpea genotypes. Pak. J. Bot., 41(2): 703-710.

Hassan, N., Wadood, S., Ullah, H., Zahoor, M., Khan, M., Khan, A. and Nisar, M. 2016. Estimation of genetic diversity in Cupressus sempervirens growing in different ecological zones of Malakand Division, KP, Pakistan. Int.
J. Biosci. 8: 15-21.

He, F. 2011. Laemmli-sds-page. Bio-protocol, e80-e80. https://doi.org/10.21769/ BioProtoc. 80

Irfan, E.T., B. Dilek, G. Hasan and S. Ahmet. 2010. Total seedstorage protein patterns of some Lathyrusspecies growing in Turkey using SDSPAGE. Pak. J. Bot., 42(5): 3157-3163.

Khan, A., M. Ali, R. U1-Haq, K. Khan, K. Gul, A. Khan, I. Khan and M. Iqbal. 2019. Evaluation of wild Rhynchosia minima (L.) DC. through morphometric and biochemical markers. Int. J. Biosci., 14(2): 7-15. https://doi.org/10.12692/ ijb/14.3.7-15

Kisana, N.S., M. Tahir, M.Y. Mujahid, I. Ahmed, A. Majid, S.Z. Mustafa and Z. Ahmed. 1999. Variability and relationship between morphophenological traits and grain yield in winter and facultative barley under stress environments. Pak. J. Biol. Sci., 2: 767-771. https://doi. org/10.3923/pjbs.1999.767.771

Lasa, J.M., E. Igartua, F.J. Ciudad, P. Codesal, E.V. Garcia, M.P. Gracia, B. Medina, I. Romagosa, J.L. Molina-Cano and J.L. Montoya. 2001. Morphological and agronomical diversity patterns in the Spanish barley correlationHereditas, 135: 217-225. https://doi. org/10.1111/j.1601-5223.2001.00217.x

Morris, P.C. and J.H. Bryce. 2000. Cereal biotechnology. Woodhead Publishing Ltd. Cambridge. UK. https://doi. org/10.1533/9781855736276

Muhammad, Z., M. Nisar and I. Noor. 2015. Genetic variations of robiniapseudoacaciaplant using sds-page. Pak. J. Bot., 47(6): 2335-2338.

Mzid, R., F. Chibani, R. Ben Ayed, M. Hanana, J. Breidi, R. Kabalan, S. El-Hajj, H. Machlab, A. Rebai and L. Chalak. 2016. Genetic diversity in barley landraces (Hordeum vulgare L. subsp. vulgare) originated from Crescent Fertile region as detected by seed storage proteins. J. Genet., 95: 733-739. https://doi.org/10.1007/s12041016-0683-5

Nisar, M., A. Ghafoor, H. Ahmad, M.R. Khan, A.S. Qureshi,H.Ali and M.Aslam.2008.Evaluation of genetic diversity of pea germplasm through phenotypic trait analysis. Pak. J. Bot., 40: 20812086.

Nisar, M., Ghafoor, A., and Khan, M.R. 2009. First proteomic assay of Pakistani Pisum sativum L. germplasm relation to geographic pattern. 
Russian J. Genet., 45(7): 805-810.

Nisar, M., A. Ghafoor, S.F. Wadood, A. Iqbal and

Nausheen.2016.Intra and inter specific profiling of Pakistani Quercus species growing in the hilly areas of district Dir Khyber Pakhtunkhwa. Pak. J. Bot., 48(1): 263-270.

Raza, A., C.M. Ayyub, M.A. Ghani and N. Ahmed. 2020. Assessment of morphological diversity among indigenous cucumber germplasm of Pakistan. Pak. J. Agric. Sci., 57(6).

Samarrai, S.M., S.M. Seyam, H.R. Mian and A.A. Dafie. 1987. Growth periods, harvest index and grain yield relationships in barley. Rachis Barley Wheat Newsletter 6: 21-24.

Shegaw, D., U. Elias and M. Hussein. 2015. Genetic variability in barley (Hordeum vulgare L.) Landrace Collections from Southern Ethiopia. IJSR. 2319-7064.

Smýkal, P., M.N. Nelson, J.D. Berger and E.J. Von Wettberg. 2018. The impact of genetic changes during crop domestication. Agronomy, 8(7):119. https://doi.org/10.3390/agronomy8070119

USDA, N. 2008. The plantss database (http:// plants.usda.gov, May 2007). National Plant Data Team, Greensboro.

Wadood, S.F., N. Hassan, A. Khaliq, Nausheen,
T. Jan, A. Ghafoor, M. Khan and M. Nisar. 2016. Genetic polymorphism in Lens culinaris collected from Malakand division Khayber Pakhtunkhwa, Pakistan. J. Biodiv. Environ. Sci., 8(2): 53-60.

Wisal, S., A. Khan, K. Gul, W. Khan, G. Nigar and M. Ali. 2019. Assessing genetic variability index among species of ACACIA through morphological and biochemical markers. Int. J. Biosci., 14: 388-401. https://doi.org/10.12692/ ijb/14.1.388-401

Zahoor, M., Nisar, M. and Islam, N. 2015. Genetic variations of Robiniapseudoaca-cia plantusing SDS-PAGE. Pak. J. Bot. 46: 2335-2338.

Zeeshan, M., U. Zain, U. Kaleem, K.B. Musa, R. Abdur and U. Riaz. 2012. Evaluation of genetic diversity in barley germplasm of Khber Pakhtunkhwa and Northern Areas on the Basis of Agro-Morphological and Biochemical traits. Int. J. Green Herb. Chem., 1(2): 186-202.

Zohary, D. and M. Hopf. 2000. Domestication of plants in the old world: The origin and spread of cultivated plants in West Asia, Europe, and the Nile Valley ( $3^{\text {rd }}$ ed.). Oxford University Press. pp. 59-69. 